\title{
Uma noite no paraíso - empoderamento feminino e cinema
}

\author{
Kyrti Ford \\ UFPE - Universidade Federal de Pernambuco
}

\section{Resumo}

Em 2006 o cineasta Karim Aïnouz lança seu segundo longa-metragem intitulado O céu de Suely. O filme, rodado na pequena cidade cearense de Iguatu, ganhou vários prêmios e solidificou a carreira de seu diretor. Através da análise de cenas da película - marcada por deslocamentos, buscas e passagens - este artigo investiga o seu processo de criação e questões relativas a gênero e empoderamento feminino que suscita.

Palavras-chave : Karim Aïnouz; Cinema; O Céu de Suely; gênero.

\section{Abstract}

In 2006 the Brazilian filmmaker Karim Aïnouz releases his second feature film entitled Love for sale (Original title, O céu de Suely). The film, shot in the small town of Iguatu, Brazil, won several awards and solidified the career of its director. Through the analysis of some of its scenes this paper aims to investigate the film's creation process as also the gender and women's empowerment issues that it raises.

Keywords: Karim Aïnouz; Cinema; Love for sale; gender.

"Eu fiquei grávida num domingo de manhã. Tinha um cobertor azul de lã escura. Mateus me pegou pelo braço e disse que ia me fazer a pessoa mais feliz do mundo. Me deu um CD gravado com todas as músicas que eu mais gostava. Ele disse que queria casar comigo. $\mathrm{Ou}$ então morrer afogado."

(Fala em off da personagem Hermila na cena inicial do filme $O$ céu de Suely.) 


\section{Ônibus, trens, caminhões, motos}

Hermila tem 22 anos e está voltando para casa. Traz consigo o filho de colo, fruto de um relacionamento que manteve enquanto morava em São Paulo, e a expectativa de começar uma vida nova na pequena cidade de Iguatu. No sacolejante ônibus em que viaja a jovem mulher carrega um semblante pensativo. Embora calada, Hermilia não é quieta. Ora está com o filho nos braços, ora está meio sentada no assento que ocupa, ora está em pé no fundo do ônibus fumando um cigarro na penumbra. As elipses da sequência da viagem além de sugerirem que o seu trajeto não é um dos mais curtos também traçam o esboço inicial de uma personagem inquieta, sempre se movimentando. A jovem mãe é uma andarilha em busca.

O céu de Suely é o segundo longa-metragem do diretor cearense Karim Aïnouz. Lançado em 2006, quatro anos depois de Madame Satã, se configura junto a esse último um dos mais expressivos expoentes do cinema da retomada. Nascido em Fortaleza, Aïnouz trafega entre sua cidade natal, São Paulo e Berlim. Esta itinerância está presente em seus filmes. "Seus personagens estão sempre em deslocamento, em busca de algo que, muitas vezes não sabem o que é" (CARNEIRO, 2014) ou como alcançá-lo. Ao longo e ao largo da jornada de Hermila passam carros, caminhões, trens, motos, homens, mulheres, terra e asfalto. A trilha sonora é marcada por sons dos motores e buzinas. Os ruídos barulhentos e nervosos acentuam a inquietação. Aïnouz optou por quase nenhum som não-diegético. A música quando presente se manifesta, na maior parte do filme, através de momentos como um rádio que toca, o karaokê a céu aberto e as noites dançantes dos personagens.

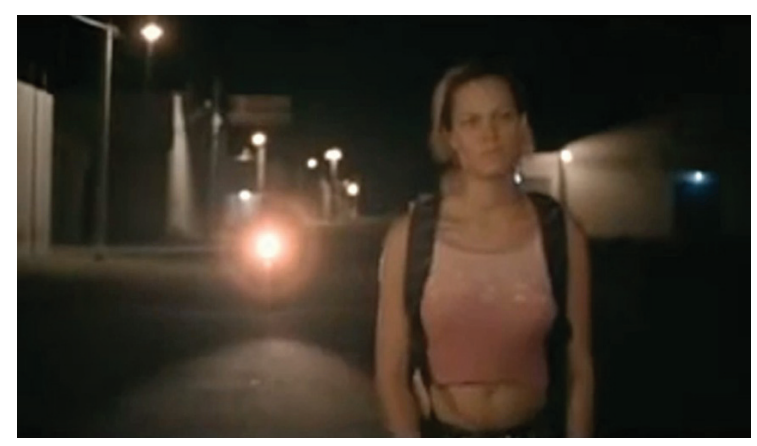

Deslocamento, busca, passagens. Hermila está sempre em movimento, seja na garupa de uma moto, nas andanças pela pequena cidade e nas idas ao telefone público a procura de notícias sobre o amante que nunca chega. Até mesmo quando está espalhada sobre o sofá na casa da avó ou deitada na cama de motel ao lado de um amante recém-reencontrado, Hermila parece prestes a dar um salto e se por andando.

Após uma desalentadora visita a rodoviária ela segue desanimada na escuridão da noite ciente agora que o pai do filho pequeno não cumprirá a promessa de juntar-se a ela. 
Em um plano sequência onde a câmera acompanha de perto a entristecida moça pela rua vazia pode-se ouvir um dos raros momentos onde uma suave música marca seus passos lentos. A música é logo substituída pelo barulho da moto de João que emerge ao fundo atrás de Hermila (Imagem 1). A sequência continua com João logo emparelhando a moto ao lado da moça. Começam um breve diálogo em que João fala que a tinha visto na rodoviária e que havia pensado que ela estava indo embora. A moça pacifica as apreensões do rapaz dizendo "Não disse a tu que vinha para ficar?", no que ele retruca duvidando, "Só vendo pra crer". Mais uma vez está marcada neste intercâmbio de falas a natureza nômade da moça.

O plano sequência segue com João desligando a moto, desmontando dela e empurrando-a enquanto caminha ao lado da moça. Os dois, João à esquerda e Hermila à direita, conversam. O rapaz oferece uma carona. Ambos param de caminhar e João se senta na moto. O humor da moça muda e um sorriso aparece em seu rosto. Para aceitar a oferta da carona ela impõe a condição de que ele compre a rifa de uma garrafa de uísque que ela vem vendendo pela cidade para angariar alguns trocados. João faz uma contraproposta: comprará a rifa se Hermila aceitar uma carona na garupa da moto. Ambos riem. João se ajeita na moto e liga o motor. "Bora?", pergunta para em seguida sair do enquadramento. Apenas o barulho da moto e uma olhadela rápida de Hermila em direção a ela indicam que João ainda está por perto.

O rapaz e sua moto retornam ao enquadramento pela direita circulando a moça por trás até parar para que ela suba. Hermila dá uma risadinha tímida e finalmente sobe na garupa da moto. Desajeitadamente João elogia o cabelo tingido da moça. Até esse instante todo o enquadramento se dá a plano médio. A altura da cintura da moça marca o fim da tela. A câmera permanece onde pararam pouco se movendo enquanto segue a moto que se distancia para o fim do quadro. O plano sequência termina sendo substituído por uma cena de uma praça com crianças brincando.

As marcações prévias de cena são inexistentes em O céu de Suely, um filme constituído por muita improvisação dentro e fora da tela. Aïnouz confessa em uma entrevista: "Eu [...] adoro improvisar." (CARNEIRO, 2014). Fátima Toledo assumiu a função de preparadora de elenco na produção. Toledo trabalhou com a personalidade dos autores preparando-os para o improviso e o acaso. "O diretor não utiliza marcações de cena. $\mathrm{Ou}$ seja, o elenco não sabe onde se posicionar para propiciar o melhor ângulo." (HESSEL, 2006). É uma construção artesanal montada em erros e tentativas, ensaios e experimentações.

Os nomes dos personagens são os nomes dos atores. Algo que não estava previsto no roteiro. João, interpretado pelo ator João Miguel, era originalmente Luis. A avó de Hermila, interpretada por Zezita Matos, chamava-se Rosário no roteiro, mas no filme tem o mesmo nome da atriz. A tia de Hermila, que no filme chama-se Maria, e que também assumiu o nome da atriz que a interpreta Maria Menezes, era originalmente Ivonete. Hermila, interpretada pela atriz Hermila Guedes, era no roteiro Suely. Nome que a personagem assume como alter-ego quando decide rifar a si mesma. Esta ideia 
foi uma "sugestão de Fátima Toledo na preparação dos atores em que cada qual chamava a outro pelo nome real. Karim, atento à situação, resolveu gravar assim mesmo, possivelmente para dar um aspecto mais natural à produção da trama." (SILVA;SANTOS, 20-?, p.4)

Abraçar o improviso e o acaso coube a todos os atores, passando por qualquer estranhamento e desconforto que tais pudessem causar. A atriz pernambucana Hermila Guedes conta que em relação à adoção dos nomes próprios dos atores ficou inicialmente assustada.

No começou assustou porque estava usando o meu nome que é tão incomum e eu achei que as pessoas iriam me confundir com a personagem. Mas depois eu falei 'ela tem tanta coisa minha, eu tenho dado tanta coisa minha, que de repente talvez seja até bonito isso. Essa fusão sem problemas de uma ser uma e a outra ser a outra'. E acho que ela é mais admirável do que eu. (GUEDES, 2007).

\section{Nascimento de Suely}

A improvisação marcou vários aspectos da produção de $O$ céu de Suely. A caracterização dos personagens - desde cabelos ao figurino - também seguiu a preferência que o diretor nutria pelo acaso. As mechas amarelas no cabelo da personagem principal, por exemplo, foi uma decisão tomada quando a equipe já estava em locação na cidade de Iguatu. Para satisfazer essa tendência à espontaneidade nas decisões Aïnouz foi mais radical ainda quando confiscou as roupas pessoais dos atores fazendo-os usar as dos personagens como suas. "Uma coisa meio louca e de certa forma diferente de ver, mas ficou interessante no final, porque isso ajudou também na composição da caracterização." (GUEDES, 2007). O real e o imaginário se confundiam na transferência dos nomes próprios dos atores para os dos seus personagens e na imposição de vestirem as roupas do figurino em frente e fora da câmera.

Aïnouz foi generoso no uso dos recursos naturais da cidade. O uso da ambientação foi previamente pensado, mas deixando larga margem para a espontaneidade. Ele quis usar o povo de Iguatu na construção de sua narrativa, porém de uma maneira em que as pessoas não soubessem que estavam endo filmadas. A intenção era para que tanto a câmera como a equipe fluísse livre. O desejo pela imersão era tal que durante o período que permaneceram em Iguatu os atores fixaram residência nas áreas que foram filmadas. Essa intimidade tão ansiada estendeu seu convite ao espectador. São muitos os enquadramentos fechados próximos aos atores em close-ups oblíquos, diagonais, escuros, trêmulos, indistintos. A cumplicidade era bem-vinda. 
Por volta dos quarenta minutos do filme, virtualmente a metade da narrativa, há uma cena em que a personagem Hermila está com sua amiga Georgina em uma diversão dançante. É noite e as duas amigas parecem se divertir bastante. O enquadramento é fechado ora na altura dos ombros, ora só nos rostos. Não há como ver exatamente onde elas estão ou quantas pessoas estão ao seu redor. Hermila e Georgina estão cercadas em um aperto de corpos dançantes. Estamos também esmagados pelo rítmico combate corpo-a-corpo. "Os planos são utilizados de modo a permitir um encontro entre o corpo do espectador e o corpo da imagem. Assim, não é um filme apenas no nível da narrativa, mas em relação às potências de afeto de cada um dos planos." (SILVA, 2012). Mateus, o amante que deixou em São Paulo, não virá mais encontrá-la. Está só com um menino pequeno para cuidar. A rifa de uísque que está vendendo e os ocasionais trocados que obtem lavando carros no posto de gasolina não são suficientes. É preciso encontrar uma outra maneira de se sustentar, é preciso seguir um outro caminho.

Na sequência da dança a câmera segue Hermila sem cortes enquanto ela masca o chiclete, emite gritinhos e deixa-se levar pelo ritmo. Ela entra e sai do foco, outros dançarinos colocam-se entre ela e a câmera que não deixa de segui-la. É apenas quando a caliente dançarina se entrega nos braços de um desconhecido que os cortes elípticos se sucedem para sugerir que os dois dedicaram certo tempo juntos a curtirem a música dançante. Os dois se afastam do grupo de dançarinos e começam a travar um colóquio intimo entre beijos e risadas. $\mathrm{O}$ enquadramento segue fechado, bem próximo ao casal convidando o espectador para testemunhar sua intimidade. Não há uso do recurso do campo e contra-campo. O espectador está lá como uma entidade invisível bem no meio do casal. Hermila aproveita o óbvio encantamento que está exercendo sobre o parceiro e lhe oferece a rifa. É nesse plano sequência que o tom do filme muda. Quando o animado rapaz lhe pergunta o nome ela lhe dá um que não é o seu. Hermila toma as rédeas do destino e dá à luz a Suely.

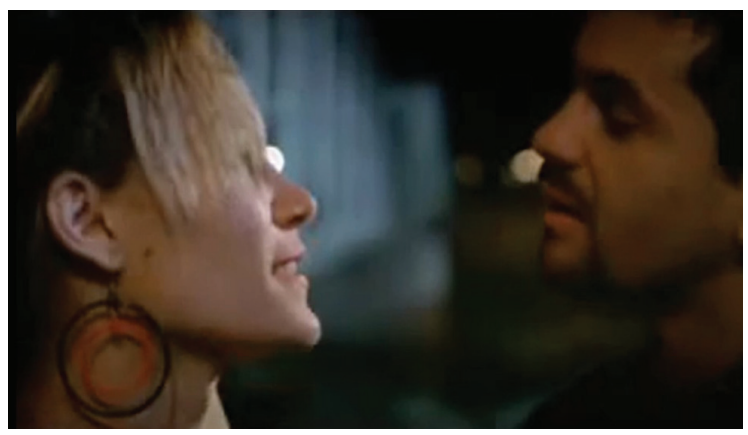

“Tá valendo. Comecei a vender hoje. Compra!”, insiste Hermila depois de se apresentar como Suely. Quando o rapaz pergunta o tipo da rifa, Hermila responde: "Uma noite no paraíso." Uma rifa diferente daquela que vendia por $\mathrm{R} \$ 2,00$ pela cidade e uma rota de fuga. A cena termina aí e a reviravolta na vida de Hermila começa. Hermila está 
rifando a si mesma. A ideia já vinha se esboçando em sua mente. Isso é indicado em uma cena anterior na qual conversa com a amiga Georgina, garota de programa, companheira temporária de caminhoneiros solitários, na qual lhe pergunta quanto cobra por seus serviços. O plano era juntar o suficiente para partir de Iguatu. Passagens para destinos mais distantes são caras. Algo que descobriu em uma consulta em um dos guichês da rodoviária.

Hermila confessa o plano apenas para Maria, sua tia. Pensa em ficar rica, comprar uma casa para si mesma e o filho. A ideia da rifa não é bem recebida pela tia que retruca espantada: “Oxe mulher! Que ideia de puta é essa?". Hermila responde que não é puta. De fato, afirma que não quer ser puta ou coisa alguma. E põe-se a acionar o seu plano. Começa a vender a si mesma usando a mesma estratégia que empregava na rifa do uísque. Passeios pela cidade e abordagens às vezes não muito sutis a potenciais cobradores. Nem sempre é bem sucedida. Há uma cena em que é escorraçada por um homem que fechava seu box de vendas em um mercado público e outra em que é confrontada por uma vendedora em uma loja de confecções enquanto tentava comprar um pequeno top. Não tarda muito para que a novidade que se espalhou pela cidade chegar aos ouvidos da avó. Questionada pela avó Hermila não arremeda o pé do seu plano e acaba sendo expulsa de casa.

O céu de Suely é dos personagens femininos. São eles que retêm mais falas e mais tempo em cena. Os homens são acessórios que permitem o transcorrer da trama que é centrada em Hermila. Karim Anïouz foi criado pela mãe e avó materna em uma família de cinco irmãs. Conta que o avô saiu para comprar cigarros e nunca mais voltou. ${ }^{1}$ A sua mãe era o homem da casa. A vida neste contexto gerou reflexões sobre o papel da mulher na sociedade.

Sempre foram questões muito presentes no meu cotidiano. Eu acho que eu fiquei muito sensibilizado [...] com a questão feminina, da igualdade, da participação da mulher no cotidiano econômico numa região como o nordeste era muito séria. E ainda tem muito a ser feito. Eu acho que O Céu de Suely, de alguma maneira, traduz um negócio que eu sempre imaginei. Porque eu acho que minha mãe deve ter sonhado tanto em ir embora, Graças a Deus ela não foi, porque foi ótimo ter sido criado por ela e tal. Mas homens vão simplesmente embora. Então a história do filme está relacionado a uma certa fantasia que eu tinha que era, poxa, seria tão bacana que, mesmo na ficção, eu pudesse imaginar o que teria acontecido se a minha mãe tivesse ido embora, entendeu?² (LIMA, 2010, p. 263).

\footnotetext{
$\alpha<\alpha<<<<<<<<<<<<<<<<<<<<\infty$

1 Em entrevista para Sumaya Machado Lima para a compilação de sua tese de doutorado As filhas do vento e o céu de Suely: sujeitos femininos no cinema da retomada.

2 Idem.
} 
Há três pequenas cenas curtas com pipas rasgadas tremulando ao sabor do vento. Estão enroscadas na fiação elétrica da rua. Uma metáfora sutil sobre a liberdade. "[...] pelos fios elétricos é movimentada a energia, a força de eletricidade em si, e as pipas, equivalentes a Hermila, feitas para voar, estão presas, imóveis." (SILVA; SANTOS, 20-?, p.8). Hermila toma as rédeas de sua vida desafiando as regras da organização familiar e social, e pela ruptura ela empodera-se. Ignorando avó, tia, vendedora enfurecida, comerciante indignado e amante enciumado ela segue em frente. Chega o momento de premiar o vencedor, um desconhecido que quase não se vê no enquadramento enquanto uma desconfortável Hermila entrega o prêmio em um quarto de motel. Na viagem de volta, após o fato consumado, vemos apenas Hermila quieta e calada quando o vencedor lhe dá uma carona. Não o vimos, apenas escutamos sua voz. Ele é irrelevante. Resta Hermila e o agora em diante.
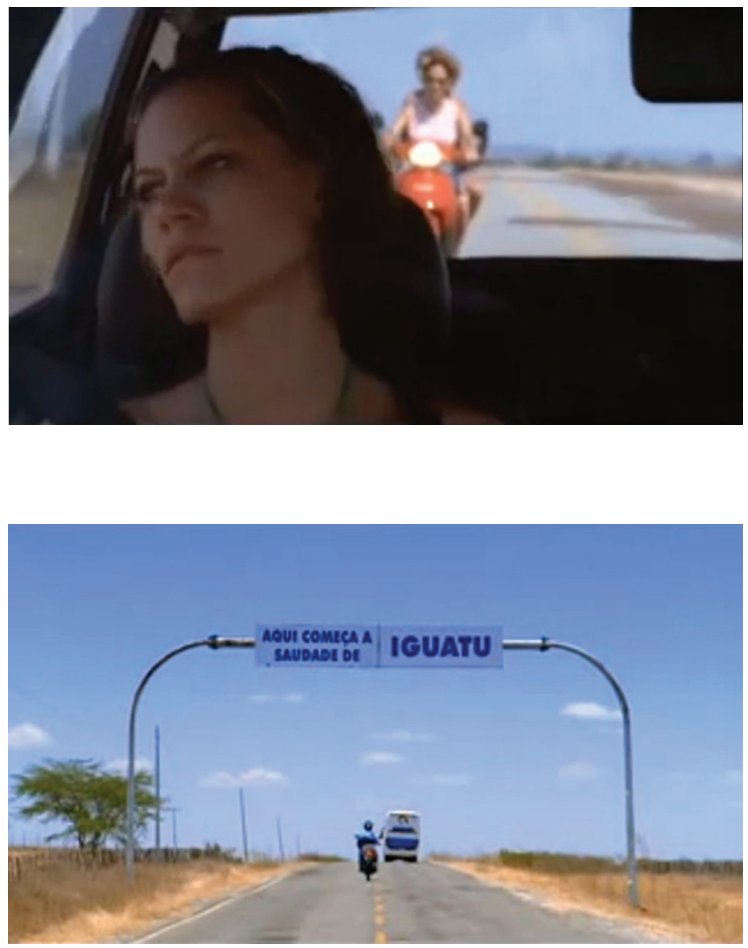

Hermila deixa o pequeno Mateus com avó que pede para ficar com a criança e vai embora de Iguatu. O filme termina com uma partida que é ao mesmo tempo um recomeço. Uma Hermila pensativa segue com a cabeça encostada na janela do ônibus que deixa a cidade. João aparece subitamente em cena montado em sua moto que dirige até se emparelhar com o ônibus. Hermila percebe sua presença no lado de fora ao lado de sua janela. Sorri de leve. Os dois, ônibus e moto, somem no horizonte. Por alguns se- 
gundos vemos apenas a placa sobre a autoestrada anunciando o limite da cidade. Final feliz? De repente a moto volta apenas com João e desaparece do enquadramento. É um "final extraordinário [que] foi pensado para desarmar nossas convenções, nossas facilidades, nosso sentimentalismo de cinema-ficção-padrão, [...]. É uma emancipação, para a personagem e para nós.” (HESSEL, 2006). Um final com potencialidades e coerente com uma mulher que decidiu recomeçar.

\section{Referências bibliográficas}

AÏNOUZ, Karim; BRAGANÇA, Felipe; ZACHARIAS, Maurício. O céu de Suely. Roteiro. Coleção Aplauso. São Paulo: Imprensa oficial, 2008. Disponível em: <http:// aplauso.imprensaoficial.com.br/edicoes/12.0.813.501/12.0.813.501>.pdf Acesso em: 19 jul. 2015.

AUMONT, Jacques; MARIE, Michel. A análise do filme. Lisboa: Texto \& Grafia Lda, 2004.

AVELLAR, José Carlos. Fora de quadro. Escevercinema. [20- -?]. Disponível em: <http://www.escrevercinema.com/Ceu_de_Suely.htm> Acesso em: 19 jul. 2015.

CARNEIRO, Gabriel. Os deslocamentos e as perturbações no cinema de Karim Aïnouz. Revista de Cinema. 2014. Disponível em: <http://revistadecinema.uol.com. br/2014/05/os-deslocamentos-e-as-pertubacoes-no-cinema-de-karim-ainouz/> Acesso em: 19 jul. 2015.

CORAL, Guilherme. O céu de Suely. Plano Crítico. 10 abr. 2014. Disponível em: <http://www.planocritico.com/critica-ceu-de-suely/> Acesso em: 19 jul. 2015.

GUEDES, J. Hermilia Guedes, protagonista de 'O céu de Suely'. [Entrevista]. 02 fev. 2007. Disponível em: <http://www.jornalapraca.com.br/arquivos/entrevistas/1033-edi-306.html> Acesso em: 19 jul. 2015.

HESSEL, Marcelo. O céu de Suely. Omelete. 16 nov. 2006. Disponível em: <http:// omelete.uol.com.br/filmes/noticia/o-ceu-de-suely/> Acesso em: 19 jul. 2015.

Omelete entrevista: Karim Aïnouz, diretor de O céu de Suely - Parte 1. Omelete. Disponível em: <http://omelete.uol.com.br/filmes/entrevista/omelete-entrevista-karim-ainouz-diretor-de-o-ceu-de-suely-parte-1/> Acesso em: 19 jul. 2015.

. Omelete entrevista: Karim Aïnouz, diretor de O céu de Suely - Parte 2. Omelete. Disponível em: <http://omelete.uol.com.br/filmes/entrevista/omelete-entrevista-karim-ainouz-diretor-de-o-ceu-de-suely-parte-2/> Acesso em: 19 jul. 2015.

KARIM Aïnouz. Filmografia. Adoro Cinema. Disponível em: $<$ http://www.adoroci- 
nema.com/personalidades/personalidade-69955/filmografia/> Acesso em: 19 jul.2015.

KARIM Aïnouz. IMDB. Disponível em:<http://www.imdb.com/name/nm0014694/> Acesso em: 19 jul. 2015.

LAURENT, Jullier. Lendo as imagens do cinema. São Paulo: Senac São Paulo, 2009.

LIMA, Santos Paulo. O céu de Suely. Revista Cinética. Disponível em: <http://www. revistacinetica.com.br/suelycartaz.htm> Acesso em: 19 jul. 2015.

LIMA, Sumaya Machado. Asfilhas dovento eo céu deSuely: sujeitosfemininosnocinema da retomada. A autora: Florianópolis, 2010. Disponível em: $<$ https://repositorio.ufsc. br/xmlui/bitstream/handle/123456789/93832/292436.pdf? sequence $=1$ \&isAllowed $=y>$ Acesso em: 19 jul. 2015.

LOVE for sale. IMDB. Disponível em:< http://www.imdb.com/title/tt0841175/> Acesso em: 19 jul. 2015.

O CÉU de Suely. Adoro Cinema. Disponível em: <http://www.adorocinema.com/ filmes/filme-128291/> Acesso em: 19 jul. 2015.

O CÉU de Suely. Direção: Karim Aïnouz Produção: João Cieira Jr. et al. Iguatu: Celluloid Dreams; Fado Filmes; Shotgun Pictures, 2006. 90 min, Dolby Digital, color., 35mm.

OLIVEIRA JR., Luiz Carlos. O céu de Suely. Contracampo - Revista de Cinema. Disponível em:< http://www.contracampo.com.br/82/festoceudesuely.htm> Acesso em: 19 jul. 2015.

SILVA, Acir Dias da; SANTOS, Eder José dos. Memória e esquecimento em $\mathbf{O}$ céu de Suely. Disponível em: <http://www.bocc.ubi.pt/pag/bocc-eder-o-ceu.pdf> Acesso em: 19 jul. 2015.

SILVA, Rodrigo Souza. Imagem, corpo e pensamento em $\mathbf{O}$ céu de Suely. O autor: Juiz de fora, 2012 Disponível em:< http://www.uff.br/facom/files/2013/05/Imagem-corpo-e-pensamento-em-o-c\%C3\%A9u-de-sueli.pdf> Acesso em: 19 jul. 2015.

SOUSA, Sandra Maria Nascimento. Gênero e (des)locamentos: o céu de Suely. Revista Pós Ciências Sociais. v.8. n. 16. jul/dez. 2011. São Luis: UFMA, 2011. Disponível em: <http://www.periodicoseletronicos.ufma.br/index.php/rpcsoc/article/view/696> Acesso em: 19 jul. 2015.

STAM, Robert. Introdução à teoria do cinema. Campinas: Papirus, 2013. 